\title{
Algunas consideraciones sobre la responsabilidad precontractual: una mirada a su regulación en Colombia, así como en otros países y la aplicación de la autonomía en negocios de ingeniería
}

\section{Some consideration about pre-contractual liability its regulation in colombia as an another countries and its application of autonomy in business engineering}

\section{Diana Patricia Arias Henao}

Abogada, especialista en derecho de las Telecomunicaciones, magister en Relaciones Internacionales, estudiante de Doctorado en Relaciones Internacionales. Docente de la Universidad Nacional de La Plata. La Plata, Argentina. ariashenaoabogados@hotmail.com

Humberto Enrique Arias Henao

Abogado, especialista en Derecho Público, magister en Derecho de los Contratos, magister en Derecho de los Negocios. Docente de la Universidad Javeriana. Bogotá, Colombia.hearias@hotmail.com

Clasificación del artículo: Revisión de Tema (Recreaciones)

Fecha de recepción: Marzo 2 de 2011

Fecha de aceptación: Noviembre 28 de 2011

Palabras Clave: compensación, daños, intereses, precontractual, regulación, responsabilidad.

Key words: compensation, damages, interest, pre-contractual, regulation, responsibility. 


\section{RESUMEN}

Las partes en un proceso de formación de contrato deben evitar causarse cualquier daño y si ocurriera, la parte que lesiona el derecho de la otra deberá compensar a la parte lesionada. En este artículo el lector encontrará los aspectos más relevantes sobre la regulación de responsabilidad precontractual en Colombia, y su regulación en el sistema legal europeo y en el americano incluyendo su naturaleza jurídica y las diferentes hipótesis estructuradas en torno a este tipo de responsabilidad civil.

\section{ABSTRACT}

The parties to a contract formation process should avoid causing any damage and if it happens, the party that violates the right of the other must compensate the injured party. In this article, the reader will find the most relevant aspects of the regulation of pre-contractual responsibility in Colombia, and its regulation in the European legal system and the U.S. including their legal nature and the various hypotheses structured around this type of responsibility.

\section{INTRODUCCIÓN}

Los seres humanos somos esencialmente seres sociales en permanente interacción, lo cual se refleja en el campo del derecho en la usual celebración de contratos para satisfacer nuestras necesidades; es así como, en el desarrollo de la cotidianidad los celebramos, como sucede al ir de compras a un supermercado o al subirnos a un bus o a un taxi, estamos celebrando contrato de compraventa y perfeccionando el contrato de transporte, en orden respectivo. En dichos contratos o situaciones ambas partes afirman su voluntad de realizarlos, puesto que mediante este acuerdo de voluntades esperan resolver sus intereses o necesidades, en una situación gana - gana.

Pero en esta vida en relación, suceden también circunstancias imputables a una de las partes, que impiden la celebración de un contrato proyectado. En el ejemplo del contrato de transporte en un taxi, la persona que levanta la mano haciendo la usual seña para que el mismo la recoja, tiene una necesidad y es la del transporte a su sitio de trabajo, pero quien maneja el taxi, tiene igualmente el interés de trasladar a esa persona al lugar que ella le indique ya que por este servicio obtendrá un pago.
Conforme lo anterior, ¿qué pasaría si el taxista recibiera múltiples señas de parada, él mismo luchará entre el tráfico con el fin de acercarse a recoger a la persona que prefirió entre aquellas que solicitaban su servicio y la persona que solicitó el servicio le manifestara que fue una broma y que no tenía la intención de tomar el taxi?

En este caso el taxista no sólo no satisfizo su interés de contratar, sino además, puso en riesgo su vehículo e incluso su integridad personal para llegar hasta la persona que solicitó su servicio en la calle, con el consecuente consumo adicional de combustible, así como la pérdida de la(s) otra(s) oportunidad(es) de contratar que se manifestaban con los llamados de otras personas, que tomaron otros servicios de taxis.

La circunstancia descrita generó en el taxista una pérdida económica que en estricto sentido jurídico debe ser indemnizada.

Otro caso, más cercano a la actividad de los ingenieros, tecnólogos y otras profesiones liberales, se manifiesta en las ofertas de contratación o a través de procesos licitatorios. Usualmente los contratos se perfeccionan por medio de un acuerdo inmediato de voluntades, donde una parte ofrece y la 
otra acepta al instante. Sin embargo, en ocasiones, las circunstancias propias del contrato a celebrar, exigen que su formación se desarrolle en un lapso mayor de tiempo que permita a los contratantes examinar sus intereses con relación al contrato proyectado y de acuerdo con esta consideración, contratar, o por el contrario, apartarse de esta intención, sin que por esta decisión se incurra en responsabilidad alguna. Lo cual se traduce en una manifestación expresa de la denominada "autonomía negocial".

Tomemos el ejemplo de un ingeniero de sistemas, interesado en prestar el servicio de desarrollo de software y que encuentra una invitación a ofertar dentro de un proceso licitatorio privado que hace una empresa a través de un periódico de circulación nacional, para que ingenieros de sistemas con una experiencia determinada presenten una oferta para el desarrollo de un programa de administración contable para una empresa de salud, oferta que deberá cumplir con unas condiciones para que la misma sea aceptada.

Es así como este ingeniero de sistemas, que a su vez estaba interesado en participar en otros trabajos de menor valía e importancia que le habían ya ofrecido, decide dejar de lado estos negocios y se concentra en la citada invitación a contratar, asumiendo los costos de la preparación de la oferta.

Una vez radicada la oferta de contrato, encuentra que en este proceso participan dos personas adicionales que igualmente cumplen con el perfil requerido. Llegado el momento de la selección de la oferta por parte de la empresa que invitó a ofertar, la misma decide, sin justificación alguna, terminar abruptamente con todo el proceso y no contratar a ninguno de los ingenieros que participaron, con la consecuente pérdida económica para quienes atendieron la invitación, representada no sólo en los costos que asumieron en la preparación de la misma, sino además en la pérdida de las oportunidades contractuales que dejaron de lado por participar en la citada contratación. Estas pérdidas deben ser igualmente indemnizadas.

Con estos dos breves ejemplos, el del taxista y del ingeniero, no es nuestro interés indicar que siempre que se inicia, lo que los autores y los jueces han denominado: el periodo precontractual, las partes deban obligatoriamente contratar, por el contrario, las partes durante dicho periodo gozan de plena libertad para contratar o no, pero limitado esta facultad al respeto de los intereses del otro, los cuales, al ser lesionados, deben indemnizarse con base en las reglas de la Responsabilidad Precontractual.

En otras palabras, es conocido que el derecho de cada persona individual va hasta donde comienza el derecho del otro, pero cuando en la etapa de formación de un contrato los derechos son vulnerados, aquel que lo lesiona está obligado a reparar los perjuicios que con su comportamiento contrario a derecho ocasionó.

El término naturaleza jurídica devela la identidad del objeto jurídico, es decir, responde a la pregunta de ¿Qué es? En este sentido, comenzaremos el análisis de la naturaleza jurídica de la responsabilidad civil precontractual; sea extracontractual, como cuando un conductor atropella a una persona, causando no solo unos daños físicos sino también unos económicos para él y su familia; o la contractual, que se genera por el incumplimiento de un contrato, como cuando habiéndose suscrito un contrato de compraventa de una bicicleta, el vendedor, quien recibió integralmente el precio pactado, no entrega al comprador la bicicleta objeto del contrato.

Es necesario resaltar que es de suma importancia, para los abogados, ubicar en una o en otra clase de responsabilidad civil a la precontractual (extracontractual - contractual), particularmente por la clase de acción que debe invocarse cuando se va a perseguir la indemnización por esta clase de daños, ante un juez o un árbitro, ya que en nuestro 
país no existe una especial acción para la responsabilidad precontractual.

La metodología que se utilizará responderá al análisis de las variables de la responsabilidad precontractual en Colombia y en otros países que pueden causarse en el ejercicio de actividades cotidianas, mediante la explicación, descripción y clasificación de las mismas.

\section{NATURALEZA JURÍDICA DE LA RES- PONSABILIDAD PRECONTRACTUAL}

Dentro del análisis doctrinal (autores) y jurisprudencial (los jueces en sus sentencias) de la responsabilidad precontractual, uno de los aspectos que mayor controversia genera aún en 2011, es el de determinar su naturaleza jurídica, presentándose principalmente dos posiciones totalmente antagónicas, con base en la tradicional clasificación de la responsabilidad civil: de un lado, un sector mayoritario de la doctrina y la jurisprudencia, en especial la italiana [1], que señala que la jurisprudencia coincide en que la naturaleza jurídica de la responsabilidad precontractual es extracontractual.

En el derecho francés [2] la teoría de la culpa in contrahendo indica que la falta cometida en la conclusión o en la negociación de un contrato se deberá equiparar a una culpa en la ejecución de una obligación contractual; lo que permitiría afirmar la responsabilidad contractual del causante de una culpa precontractual. Al contrario, en razón de que el contrato no existe todavía, la responsabilidad precontractual no es sino una aplicación de la responsabilidad extracontractual de los arts. 1382 y 1383 del Código Civil.

Para confirmar lo anterior, el autor hace una amplia citación de jurisprudencia francesa, a nivel del derecho comparado, le atribuye a esta responsabilidad un carácter extracontractual, debido a que esta responsabilidad nace en un momento an- terior a la presencia de un contrato perfeccionado o suscrito. Siguen esta tendencia, entre otros, los autores Larroumet, Miccio [3], Bianca [4], Checchini [5], Asua [6], Melich-Orsini [7], Sglitz [8] quienes son los principales exponentes.

Otro sector, ha reconocido un carácter contractual al incumplimiento de la obligación surgida en un escenario precontractual. El alemán Rudolf Von Iherin reconocido como el "creador" del Instituto de la Responsabilidad Precontractual, lidera la posición que afirma que la responsabilidad civil precontractual surge durante la elaboración del referido contrato o negocio jurídico, vulnerándose algo más que el deber general de no dañar al otro o neaminem leadere, sobre el cual gira la responsabilidad extracontractual, ya que el daño que se produce no es a una persona indeterminada, sino por el contrario, este se genera en una persona determinada, el tratante. Limitación o concretización del neaminem leadere, al establecerse el deber de no dañar a una persona en específico, tal y como sucede en la responsabilidad contractual. Siguen esta tendencia, entre otros, autores Faggella [9], Salleilles [10], Visintini [11], Scognamiglio [12], Alpa [13], Claro [14], De la Puente y Lavalle [15].

Es bastante lógico que en Alemania se haya tenido que acudir al terreno contractual, si se tiene en cuenta que en su sistema de tipicidad de los daños extracontractuales resarcibles (enumerationsprinzip) no entran los daños primariamente patrimoniales (que son precisamente ante los que nos encontramos en la gran mayoría de los casos en que se experimenta un perjuicio en la fase de preparación de los contratos), sino solo los derechos subjetivos absolutos (la vida, el cuerpo, la salud, la propiedad o cualquier otro derecho de la persona, § 823-1), en general.

Adicional al anterior argumento, entre los fundamentos para considerar a esta responsabilidad como de carácter contractual se encuentran los siguientes: 
- Pacto implícito: los seguidores de esta tendencia consideran que durante las negociaciones surge un pacto entre los tratantes que los obliga a actuar conforme a la buena fe y a no retirase de estas de forma injustificada, en el que el incumplimiento de este pacto o acuerdo de voluntades se asimila al incumplimiento de un contrato.

- Buenafe contractual: los adherentes a esta teoría se sustentan en que el principio de la buena fe que las partes deben observar durante las negociaciones precontractuales es de carácter contractual, por lo que su incumplimiento genera una responsabilidad de este género.

Se puede entonces observar que la selección de la naturaleza jurídica para la responsabilidad precontractual es confiada a la jurisprudencia y la doctrina; es una constante, en los diferentes ordenamientos jurídicos vigentes (sistema jurídico de los países), que el legislador (quien hace la ley) no se inmiscuye en esta labor; no obstante, se presentan algunas esporádicas excepciones, es el caso del Código Civil alemán, que al hacer una descripción taxativa de las hipótesis de responsabilidad civil extracontractual, omitió expresamente a la responsabilidad precontractual.

De lo anterior se puede concluir que la tendencia, casi unívoca, es la de ubicar a la responsabilidad precontractual dentro de los dos grandes géneros de responsabilidad civil, sin embargo, paralelamente han surgido otras opiniones, que apartándose de la tradicional división, consideran a la responsabilidad precontractual como un tercer genero de responsabilidad civil o tertium genus, a raíz de las características propias de esta y en especial, por la dificultad de encuadrar certeramente su naturaleza jurídica, debido a los fuertes argumentos de los sectores tradicionales.

Esta tercera posición, aunque minoritaria, ha alcanzado en los últimos años una interesante relevancia, principalmente en la doctrina italiana, encontrándose autores como a Giannini [16], Bigliazzi [17], Sacco y Visintini.

En Colombia, los profesores Arturo Valencia Zea y Álvaro Ortiz Monsalve [18] adhieren a esta posición, considerándola como un tipo de

responsabilidad especial que no es necesario derivarla de la responsabilidad contractual o de la extracontractual, sino simplemente del principio que manda que así como los contratos deben ejecutarse de buena fe, así mismo debe procederse en su formación, o sea obrar con la suficiente corrección y diligencia exigida por los usos sociales.

Debemos manifestar pues, que si bien todas las anteriores posiciones gozan de argumentos contundentes, al no existir un contrato en el momento en que surge esta responsabilidad, podremos decir, que nos encontramos frente a una responsabilidad de carácter extracontractual ya que con su ocurrencia se está lesionando el deber de no dañar al otro al haber trasgredido su derecho e irrumpir en los derechos de su co-tratante.

Pero dejando de lado aspectos de exclusiva técnica jurídica, el derecho ha querido simplificar a sus operadores la forma de determinar cuando ocurre o no la responsabilidad precontractual, es decir, cuando un tratante vulnera los derechos del otro y de esta manera estaría obligado a reparar dichos perjuicios, por lo que pasamos a ver a continuación las diferentes hipótesis de responsabilidad precontractual, cuya ocurrencia determina la obligación de reparar los perjuicios ocasionados durante la celebración de un contrato.

\section{HIPÓTESIS DE RESPONSABILIDAD PRECONTRACTUAL}

Los diversos ordenamientos jurídicos han reconocido como hipótesis de surgimiento de responsabilidad precontractual a los siguientes supuestos 
de hecho: en primer lugar, a la violación del deber de buena fe precontractual; en segundo lugar, al retiro injustificado de las negociaciones preliminares o tratativas y, en tercer lugar; a la revocatoria de la oferta y de la aceptación.

\subsection{Violación al principio de la buena fe precontractual}

El legislador contemporáneo acude al principio general de la buena fe como una forma de limitar la autonomía y libertad de las partes que tiene como fin, lograr una contratación conveniente a sus intereses, exigiéndoles mantener una conducta suficientemente respetuosa de los intereses del otro, con el objeto de que las negociaciones precontractuales no se convierta en una fuente productora de daños. Cualquier vulneración a este deber, genera automáticamente la obligación de reparar los daños ocurridos al interés del tratante afectado.

De acuerdo con lo anterior, el legislador impone a los contratantes la observancia de este deber de dos formas: de un lado, mediante la consagración normativa expresa de esta hipótesis de responsabilidad, traduciéndose en la tendencia preponderante en recientes codificaciones civiles y en diversas experiencias de unificación del derecho, donde el artículo 1337 del Codice Civile italiano de 1942, estipula: "Tratativas y responsabilidad precontractual. Las partes, en el desarrollo de las tratativas y durante la formación del contrato, deben comportarse de acuerdo con la buena fe (traducción propia)", que se constituye como la primera disposición en establecerla, adoptándose luego por los artículos: 227 del Código Civil de Portugal de 1966, 465 del Código Civil boliviano de 1976, 1362 del Código Civil peruano de 1984, 1198 del Código Civil argentino de 1869 (reformado por la Ley 17.711) y el artículo 920 del proyecto de reforma (1998) del mismo Código, 689 del Código Civil paraguayo de 1987,
1375 del Código Civil de Quebéc de 1994 y 863 del Código de Comercio colombiano de 1971; así como por los artículos, 1.7 de los Principios de UNIDROIT y 6o del Proyecto Preliminar del Código Europeo de los Contratos.

De otro lado, en ausencia de disposición expresa que consagre el mencionado supuesto de responsabilidad precontractual, la jurisprudencia y la doctrina acuden a la aplicación por analogía de la norma general que consagra el principio de buena fe contractual, para configurar esta primera hipótesis de responsabilidad precontractual. Tal y es el caso del artículo 1134 del Código Civil francés de 1804, que es la norma general del deber de buena fe contractual y que es seguido por los artículos: 242 del BGB (Código Civil alemán) de 1900, 1258 del Código Civil español, 1546 del Código Civil chileno, 1291 del Código Civil uruguayo de 1868, 1603 del Código Civil colombiano de 1873, 1160 del Código Civil venezolano de 1942, 1796 del Código Civil mexicano. En este caso se está refiriendo al Código Civil para el Distrito Federal en materia común y para toda la República en materia federal, 1210 del Código Civil de Puerto Rico de 1930, 1480 del Código Civil salvadoreño de 1860, 1546 del Código Civil de Honduras de 1906, 1519 Código Civil de Guatemala de 1967, artículo 39 del Proyecto Franco - Italiano de Código de las obligaciones y de los contratos de 1927, entre otros.

Con relación al contenido del principio de la buena fe precontractual, se ha considerado que a partir de este surgen otros deberes a observarse desde el primer momento de la formación del contrato. Para su exposición, se trae a colación la clasificación que hace el jurista italiano Massimo Bianca en su libro Il Contratto, quien admite que la buena fe precontractual se especifica, inicialmente, en dos fundamentales deberes, uno, el de lealtad y otro, el de corrección. Del primero provienen los deberes de información, confidencialidad y claridad; y del segundo, el deber de cumplimiento 
de los actos necesarios para la validez y eficacia del contrato.

\subsubsection{Deber de lealtad}

Deber de información: en virtud al deber de información, las partes durante las negociaciones precontractuales han de mantenerse recíprocamente informadas de todas las circunstancias del contrato objeto de negociación, para de esta forma contar con mayores elementos de juicio que les permita decidir si se contrata o no. Las circunstancias a informar son aquellas de hecho y de derecho que otorguen a las partes, de un lado, la certeza de celebrar un contrato válido y eficaz, y del otro, que le permita establecer si tiene o no el verdadero interés en realizarlo.

Es una constante la ausencia en los códigos civiles europeos y latinoamericanos, de una consagración expresa del deber de información a observarse durante el desarrollo de la formación del contrato, sin embargo, la doctrina ha considerado que en los parágrafos 122 y 307 del BGB se establece una de las hipótesis de culpa in contrahendo, la omisión de información concerniente a la imposibilidad e invalidez del contrato que se concluye, cuando el contratante lo supiese o debiere saberlo, constituyéndose como antecedente del artículo 1338 del Codice Civile italiano de 1942 que dispone el deber de indemnizar los daños que se produzcan por la omisión de información de las causales de invalidez del contrato y aunque expresamente no consagra que su aplicación sea en el ámbito precontractual, la doctrina ha sido consistente en afirmar que así lo es. Sigue estos lineamientos el proyecto de reforma de 1998 al Código Civil argentino, en su artículo 927, consagrando expresamente el referido deber. No obstante lo anterior, en la mayoría de las codificaciones civiles vigentes se presentan disposiciones tácitas del deber precontractual de información, al consagrarse diferentes situaciones que se en- marcan dentro de las hipótesis del mismo. Es el caso, entre otros, de la responsabilidad por vicios redhibitorios, ya que el contratante tiene el deber de comunicar los vicios ocultos de la cosa que conociera o debiera conocer y de reparar los daños que esta omisión ocasionare, en virtud de la obligación de saneamiento en cabeza de quién tuviere a su cargo el deber de informar.

Según el jurista francés P. Jourdain, el deber de informar los vicios comienza desde las tratativas, cuyo único límite lo constituiría el denominado vicio aparente, o sea, aquél que es conocido o que normalmente se hubiese podido conocer, bien porque es ostensible o porque ha podido surgir a partir de un examen superficial, pero atento de la cosa objeto del futuro contrato.

De la misma forma nos podemos referir al contrato de seguro, ámbito en el cual este deber es de capital importancia, tal como se puede deducir de la relación entre reticencia y agravación del riesgo, ya que el asegurado es el titular del deber pasivo de comunicar al asegurador todas aquellas circunstancias que puedan incidir en la apreciación del riesgo; la omisión o falsedad de la información acarreará consecuencias jurídicas para el asegurado, como la anulación del contrato (artículos 1892 y 1893 del Codice Civile italiano, 511 del Código de Comercio venezolano, 1058 y 1161 del Código de Comercio colombiano), la nulidad del mismo (artículos 5 y 131 de la Ley 17.418 de Argentina) o la pérdida del valor del seguro y la devolución de las sumas entregadas (artículos 1443 y 1444 del Código Civil del Brasil).

La regulación expresa del deber precontractual de información en los derechos nacionales ha sido confiada a ordenamientos especiales, tal es el caso de la normatividad encargada de la regulación de los contratos de consumo o también conocidas como leyes de protección al consumidor (particularmente en el derecho latinoamericano), las cuales lo desarrollan exhaustivamente. El contenido 
de este deber a cargo de los empresarios en esta clase de contratos se traduce, en la etapa antecontractual, en los consejos dirigidos al consumidor que puedan incidir en su interés a contratar y una vez perfeccionado el contrato, en lo relativo a la forma de uso, precauciones, elementos integrantes, instrucciones, etc., del objeto del contrato.

\subsubsection{Deber de claridad}

Este deber impone a las partes la utilización de un lenguaje que sea susceptible de ser plenamente comprendido por el otro, es decir, que las informaciones intercambiadas por los tratantes sean perfectamente inteligibles, que no se presten a una mala interpretación. En general, la dificultad en el lenguaje, desde un punto de vista objetivo, no debe ser factor que impida la formación de un contrato, no obstante, lo que se busca con este deber es evitar que uno de los contratantes, aprovechándose de la ignorancia de su contrario, logre que se aprueben cláusulas en total desproporción e iniquidad, que redunden en beneficios para uno y en perjuicios para el otro.

\subsubsection{Deber de confidencialidad o secreto}

La confidencialidad o secreto es un tercer deber precontractual que impone a los contratantes abstenerse de divulgar los hechos o informaciones de carácter reservado, que hayan sido conocidos a causa de las negociaciones precontractuales, y que divulgados, puedan ocasionar perjuicios para el otro; no obstante, en principio, las informaciones que se intercambian las partes no son confidenciales, teniendo en cuenta que cada una de ellas es libre de decidir cuáles hechos son pertinentes de ser revelados y cuáles no, por tanto, este tipo de información puede ser utilizada por el otro para ser comunicada a terceros o para sus propios fines. Pero es posible poner un límite a esta libertad, por medio de la advertencia de que la información que se está brindando a causa de las negociaciones es confidencial, por lo que esta no podrá ser divulgada o usada para fines diferentes a los dispuestos por quien la proporciona.

Ahora bien, aún en ausencia de manifestación expresa del carácter confidencial de la información, la parte que la recibe puede encontrarse sujeta a este deber de forma tácita; tal es el caso de que la información tuviese una naturaleza especial que impidiere que fuese objeto de divulgación, o por el carácter técnico o profesional de las partes, como sucedería en el caso de un mediador, quien está obligado al secreto, debido a que la actividad que desarrolla en las negociaciones es de carácter profesional y las noticias reservadas que recibe, lo hace en el ejercicio de su profesión, por tanto no puede revelarlas; lo mismo sucede en relación con los secretos personales de los tratantes.

No se presenta consagración normativa expresa de este deber, ni en las legislaciones civiles europeas, ni en sus homólogas latinoamericanas, por lo que se considera regulada con base en las disposiciones que sobre la buena fe precontractual o contractual, según el caso, establezcan los códigos.

\subsubsection{Deber de corrección}

Deber de realizar los actos necesarios para la validez o eficacia del futuro contrato: deber que surge particularmente de la corrección o salvaguardia que deben mantener las partes durante el desarrollo de las negociaciones. Su contenido se concluye de su propia denominación.

Su inobservancia se configura como una de las más típicas hipótesis de responsabilidad precontractual, que se verifica cuando el contratante no cumple con los actos que de parte suya son necesarios para la validez o eficacia del futuro contrato. Bajo este aspecto se ha considerado, principalmente por la doctrina italiana, que una de las más frecuentes circunstancias de vulneración a este deber lo constituye la omisión dolosa o culposa 


\section{|re-creaciones}

del contratante que estando obligado a hacerlo no presenta una solicitud necesaria para obtener una autorización pública so pena de nulidad o ineficacia del contrato.

\subsection{Retiro injustificado de las tratativas o negociaciones preliminares}

Continuando con el análisis de las diversas hipótesis de responsabilidad precontractual, nos encontramos ahora con el retiro injustificado de las negociaciones preliminares o tratativas. Para comenzar con su exposición es necesario mencionar brevemente que la doctrina preponderante, al igual que la jurisprudencia, y en menor grado la ley, ha considerado que la etapa antecontractual o de las negociaciones precontractuales se divide en dos partes: la primera, las tratativas o negociaciones preliminares, que se inicia a partir de los primeros acercamientos de las partes hasta antes de la presentación de la oferta de contrato; y la segunda, que comienza con la oferta de contrato hasta la conclusión del mismo, la cual es denominada como la de formación del contrato.

Es pertinente reiterar que durante las negociaciones preliminares la regla general es la libertad de las partes, en la que cada uno tiene la facultad de continuar o retirarse de estas a su conveniencia, ya que no existe ninguna obligación entre ellos de celebrar un futuro contrato; el único límite que se ha de observar es la buena fe, que se lesiona cuando se presenta una ruptura injustificada de las negociaciones y que se convierte en causal de responsabilidad precontractual cuando esta conducta ha producido daños y perjuicios, los cuales deben ser reparados.

De esta forma, el aspecto necesario de esta hipótesis está en determinar el significado de la expresión injustificada. En este sentido se ha considerado que el rompimiento de las negociaciones no produce responsabilidad por el solo hecho de que esta se hubiese realizado sin un justo motivo, ya que como se ha dicho, los tratantes son libres de retirarse de las negociaciones en cualquier momento previo a la celebración del contrato.

Lo que da lugar a la obligación de reparar es que el retiro se haga por medio de un comportamiento reprochable que ha causado daños al otro, en donde lo censurable no es el retiro de las tratativas sino la forma como este se ha hecho, habiéndose despertado una confianza razonable de celebrar un futuro contrato en la víctima del daño, confianza que, según la doctrina y la jurisprudencia, surge una vez que en el desarrollo de las negociaciones las partes hayan logrado acordar los elementos esenciales del proyectado contrato, restando solamente definir detalles accesorios o de menor importancia. Lo mismo puede decirse cuando el acuerdo es totalmente alcanzado, faltando únicamente traducirlo en la forma escrita necesaria para que sea válido.

El surgimiento de la responsabilidad precontractual por el retiro injustificado de las tratativas no ha sido objeto de consagración expresa en las codificaciones civiles de Latinoamérica y Europa, pero a partir de consideraciones jurisprudenciales y doctrinales, los supuestos de hechos que se encuadran dentro de las hipótesis de responsabilidad precontractual en comento, son regulados por las disposiciones que sobre la buena fe precontractual o contractual, según el caso, establezcan estos códigos, ya que este retiro es considerado como una hipótesis de vulneración a la buena fe a observarse en las tratativas.

\subsection{Revocatoria de la oferta y de la aceptación}

Avanzando por las negociaciones precontractuales, encontramos otra de las hipótesis de responsabilidad precontractual, la revocatoria de la oferta y de la aceptación; hipótesis ampliamente desarrolladas por la doctrina, la jurisprudencia y la legislación. 
La ocurrencia de la responsabilidad precontractual por la revocatoria de la oferta depende en gran medida del régimen que establezca el ordenamiento jurídico en particular, es decir, si la oferta es irrevocable o por el contrario si no lo es.

En este sentido ha considerado la doctrina y la jurisprudencia mayoritaria, que en los casos de oferta revocable es un derecho de los contratantes el retirarse de las negociaciones precontractuales, no obstante lo anterior, el derecho impone límites a esta facultad y surgirá la obligación de indemnizar los daños ocurridos por esta revocatoria cuando:

- es realizada vulnerando la buena fe precontractual (igual criterio se adopta para considerar la revocatoria de la aceptación como hipótesis de responsabilidad precontractual).

- cuando se hace legítimamente pero se ha iniciado de buena fe la ejecución del contrato por parte del aceptante y luego se revoca la oferta (doctrina italiana).

- cuando al ser una oferta simple, se revoca sin permitírsele al aceptante un lapso de tiempo para decidir si la acepta o no, siendo esta última una consideración de la doctrina y la jurisprudencia francesa. Ordenamientos que parten de la regla de la revocabilidad de la oferta se encuentran: el español (art. 1262 del Código Civil), italiano (art. 1328 in. 1 del Codice Civile), argentino (arts. 1149 y 1150 del Código Civil), uruguayo (arts. 1265, 1266 y 1267 del Código Civil), colombiano (art. 846 del Código de Comercio, considerado así por la doctrina y la jurisprudencia), chileno (arts. 97 y 98 del Código de Comercio), de Puerto Rico (art. 1214 del Código Civil), venezolano (art. 1137 del Código Civil), libanés (art. 179 del Código de las obligaciones y de los contratos), la Convención de Viena de 1989 sobre compraventa internacional de mercaderías (art. 16). Sin em- bargo, estos ordenamientos establecen límites a esta revocabilidad, estableciendo fenómenos especiales de irrevocabilidad de la oferta.

Con relación a los casos en que se considere a la oferta como esencialmente irrevocable existen dos posiciones antagónicas, de un lado, se establece que al ser irrevocable la oferta, la revocatoria de esta no tendría efectos y el contrato se perfeccionaría, sin dar a lugar a la ocurrencia de responsabilidad precontractual, a lo sumo de responsabilidad contractual, en el caso que el oferente se mantenga en su negativa, incumpliendo así el acuerdo contractual.

De otro lado, la opinión contraria (esencialmente la jurisprudencia italiana) considera que si hay lugar al surgimiento de responsabilidad precontractual porque con la revocatoria se estaría vulnerando el principio de la buena fe, obligándose así la parte culpable a indemnizar los daños que con su acción produjo a su contraparte. Ordenamientos que parten de la regla de la irrevocabilidad de la oferta: entre ellos los Código Civiles de: Alemania (§ 145), Austria (art. 862), China (arts. 95 y 154), Portugal (art. 653), Brasil (arts. 1080 y 1081), Perú (art. 1382), México (arts. 1084 y 1086), Cuba (art. 317 n. 2); los Códigos de las obligaciones de: Polonia (arts. 63 y 66), Suiza (arts. 3 al 7), Turquía (arts. 3 al 7); el proyecto de reforma de 1998 al Código Civil argentino (art. 925).

Es pertinente hacer referencia a la antinomia consagrada en el inciso $1^{\circ}$ del artículo 846 del Código de Comercio colombiano. Que sostiene: "La propuesta será irrevocable. De consiguiente, una vez comunicada, no podrá retractarse el proponente, so pena de indemnizar los perjuicios que con su revocación cause al destinatario".

Disposición frecuentemente criticada ya que parte del supuesto de la irrevocabilidad de la propuesta, estableciéndola como regla general; no obstante, a renglón seguido consagra una solución 


\section{re-creaciones}

contraria a este primer postulado, permitiendo la revocación de la oferta so pena de indemnizar daños y perjuicios, abandonando de esta forma, las características propias del concepto de irrevocabilidad de la oferta. Al respecto, la doctrina preponderante, ha decidido ubicar esta norma, dentro de la tendencia que admite como regla general la revocabilidad de la oferta [19].

En el mismo sentido se expresa el artículo 847 del Código de Comercio colombiano, al establecer que las ofertas de mercaderías, con indicación del precio, dirigidas a personas indeterminadas, en circulares, prospectos o cualquiera otra especie similar de propaganda escrita, no serán obligatorias para el que las hace, es decir, son esencialmente revocables, sin embargo, el artículo 848, reza:

Las ofertas que se hagan en vitrinas, mostradores y demás de pendencias de sus establecimientos con indicación del precio y de las mercaderías ofrecidas, serán obligatorias mientras tales mercaderías estén expuestas al público. También lo será la oferta pública de uno o más géneros determinados o de un cuerpo cierto, por un precio fijo, hasta el día siguiente del anuncio, respecto de las ofertas que se hagan en vitrinas, parte del principio contrario, el de la irrevocabilidad de la oferta, al establecer que el precio de las mercancías ofrecidas deben mantenerse mientras tales mercancías estén expuestas.

Para finalizar, afirmamos que los supuestos de hecho presentados son aquellos que el derecho ha considerado hasta el momento, como hipótesis de responsabilidad precontractual, más pueden no ser los únicos, ya que del estudio de este instituto jurídico es posible que surjan otras situaciones que se configuren como tales.

\section{CONCLUSIÓN}

Los seres humanos para satisfacer sus necesidades e intereses desarrollan procesos de gestación que terminarán en un contrato, y durante el transcurso del mismo están llamados a evitar cualquier clase de daño, y si se causa, se contempla la obligación de reparar ese daño.

Suele ubicarse a la responsabilidad pre-contractual, aquella que se general durante el proceso de gestación que llevará al contrato, dentro de la responsabilidad civil extracontractual o bien, dentro de la responsabilidad civil contractual. No obstante, esta tradicional división ha encontrado nuevas posturas, como aquella que afirma que la responsabilidad civil precontractual no puede ubicarse en ninguna de las responsabilidades descritas, sino que por el contrario, su composición compleja requiere de clasificarla dentro de un tercer género de responsabilidad civil o tertium genus.

Respecto a lo anterior, reiteramos que en nuestra posición, la naturaleza jurídica de la responsabilidad civil precontractual es extracontractual, puesto que no existe contrato en su ámbito de origen y desarrollo.

En síntesis, la responsabilidad civil precontractual se causa cuando el tratante vulnera los derechos del otro y de esta manera se obliga a reparar tal vulneración.

Las causas que generan la vulneración en la etapa precontractual son: la violación del deber de buena fe precontractual; el retiro injustificado de las negociaciones preliminares o tratativas, $\mathrm{y}$, la revocatoria de la oferta y de la aceptación. 


\section{REFERENCIAS}

[1] G. Patti, S. Patti, Trattato Breve de la responsabilità civile. Padova, 2009.

[2] C. Larroumet, Teoría General del Contrato, (v. I-II, trad. de Jorge Guerrero R.), Bogotá, Colombia, 1993.

[3] R. Miccio, I diritti di credito-Il contratto, Torino, Italia, 1977.

[4] M. Bianca, Diritto Civile. Il Contratto, t. 3, Milano, Italia, 1998.

[5] Checchini, Rapporti non vincolanti e regola di corretezza, Milano, Italia, 1997.

[6] C. Asua, La culpa in contrahendo, tratamiento en el derecho alemán y presencia en otros ordenamientos, responsabilidad civil contractual y extracontractual, Madrid, España, 1989.

[7] J. Melich, Doctrina general del contrato, Caracas, Venezuela, 1993.

[8] G. Stiglitz y R. Stiglitz, Responsabilidad Precontractual, Buenos Aires, Argentina.

[9] G. Faggella, Dei periodi precontrattualli, en Studi giuridici in onore di Carlo Fadda, t. III, Napoli, Italia, 1906.

[10] R. Saleilles, "De la responsabilité précontractuelle", en Revue Trimestrielle de Droit Civil, París. Citado por G. Stiglitz y R. Stiglitz, Responsabilidad Precontractual, Buenos Aires, Argentina, 1907.
[11] G. Visintini, La reticenza nella formazione dei contratti,Istituto della Enciclopedia Italiana, Fondata da Giovanni Troccani Roma, Italia, 1972.

[12] R. Scognamiglio, Dei contratti in generale, Bologna, Roma, Italia, 1970.

[13] G. Alpa, Responsabilidad civil contractual y extracontractual, Madrid, España.

[14] L. Claro, Explicaciones de derecho civil chileno y comparado, de las obligaciones, Santiago, Chile, 1979.

[15] De la Puente, M. y Lavalle. El contrato en general, Comentario a la sección primera del libro VII del Código Civil. Lima, Perú, 1996.

[16] M. Giannini, "La responsabilità precontrattuale dell'amministrazione publica", en Raccolta di scritti in onore di A. Jemolo, v. III, Milano, Italia, 1963.

[17] G. Bigliazzi, Contributo ad una teoria dell'interesse legitimo nel diritto privato, Milano, 1967.

[18] Z. Valencia y A. Ortiz, Derecho civil, de las obligaciones, t. III, 9a ed., Bogotá D.C., Colombia, 1998.

[19] A. Alessandri, De los Contratos, Santiago. 